\title{
Knowledge Management and Academic Performance in Indian Public Schools
}

\author{
Arunima Kambikanon Valacherry ${ }^{1}$ and P. Pakkeerappa ${ }^{2}$ \\ ${ }^{1}$ Central University of Kerala, Kasargod, India \\ ${ }^{2}$ Mangalore University, Mangalagangothri, Karnataka, India \\ vibi.arunima@gmail.com \\ ppkmba@yahoo.co.in
}

\begin{abstract}
Knowledge Management (KM) systems were implemented widely in corporate organizations for past three decades, but there is little research on KM in schools. The key objectives of this study are to identify the major components of School Knowledge Management and analyze the impact of KM in secondary education on academic performance, based on the perception of school teachers. The survey-based study is conducted in government schools of an Indian State. Exploratory Factor Analysis and Binary Logistic Regression methods are used to identify the KM factors and their impact on academic performance. This study identified the processes and enablers of school KM and its impact on academic performance. Academic performance, being mentioned as the primary outcome of School KM has not been empirically tested from a School KM perspective earlier. Knowledge creation, technology infrastructure and teacher's competency are identified as KM variables that can significantly influence the Academic Performance and therefore the schools can initiate policies and methods to improve these vital factors.
\end{abstract}

Keywords: School Knowledge Management, Academic Performance, Secondary Education, Logistic Regression

\section{Introduction}

Knowledge Management (KM) is a concept that prominently arose in the 1990s. KM initiatives in organizations primarily target on improved performance, competitive advantage, innovation, organizational learning, process integration and continuous improvement of the organization (Davenport and Prusak, 1998; Hatch and Dyer, 2004; Wiig 2004). KM was important in improving the performance of human resources in corporate organizations, both manufacturing and services. But KM in education is comparatively under-researched especially in schools as, they lagged behind to accept KM as a practice (Chu, 2016a; Supermane and Tahir, 2018). Therefore, this study analyzes KM in education, focusing on the government schools in India. School KM was well defined by Cheng (2015) as a set of relatively new organizational activities that make use of knowledge as an important resource to improve organizational behaviours, collaborative learning, student learning, teaching processes, improved decisions and collegial relationships that enable schools to improve their overall performance.

During 1990s the concept of learning organizations received more attention as a way to restructure educational organizations in terms of better autonomy and improved academic performance (Fullan and Fullan, 1993; Vandenberg, 1993; Louis 1998; Karsten, Voncken and Voorthuis, 2000). It was identified that rather than implementing planned projects for change, the schools should themselves bring change with each team member contributing to change through learning initiatives (Karsten, Voncken and Voorthuis, 2000; Fauske and Raybould, 2005).In this context KM acts as that management practice whose objective is to enhance the organizational learning process in schools for creating a sustainable innovation system through various processes such creation, storage, sharing and application of knowledge (Firestone and McElroy, 2004). Schools can therefore be also called knowledge organizations where teachers, students, parents and staff form the major stakeholders and the role of teachers as knowledge workers is more significant (Tahir et al., 2013).

The education sector in India can be classified into three levels namely school education, graduation and higher education. There are private schools managed by private stakeholders and also public schools purely organized and managed by the government. A vast majority of the Indian students depend on public education because of low cost and accessibility compared to private schools. As far as the economic and social growth of a nation is concerned, the opportunity and quality of secondary education need to be focused on as they contribute significantly to the social, cultural, moral and technological orientation of an individual (Chu, 2016a). Many international and national organizations have started considering the importance of secondary education for developing a creative and skilful youth. 
The EFA Global Monitoring Report 2015 presented by UNESCO, with the theme "Education for all', clearly states that the educational priorities and actions initiated after 2015 would be intended to contribute to the final formulation of 'Sustainable Development Goals' in education. The first goal is stated as follows: 'By 2030, ensure that all girls and boys complete free, equitable and quality primary and secondary education leading to relevant and effective learning outcomes'. This decision was as a result of observation of outcomes from various assessments conducted at national and international levels on quality of secondary education. It is alarming to find that millions of children struggle to acquire even minimum levels of basic skills, which indicates a lack of planning on educational quality improvement (EFA Global Monitoring Report, 2015). Although the secondary curricula have the potential of providing spaces for exploration and experimentation, they are hardly implemented in the majority of cases. This results in long-term consequences where students lack the pragmatic skills to excel in future.

Now from a national perspective, in India, The Ministry of Human Resource Development (MHRD) has taken a number of initiatives including various Centrally Sponsored Schemes (CSS) to enhance quality of education in 2014. About Secondary Schools (IX-X) under the educational scheme, one of the priorities is to improve the quality of secondary education despite providing educational access to more students in the country. Financial assistance is provided to public schools to improve the physical and academic infrastructure and also for managing all issues of pedagogy focusing on academic performance through professional development of teachers, teaching methodology, assessment and evaluation methodology, teacher training, research in pedagogy, curriculum design and effective pedagogy.

In this context, it is important to analyze the KM practices in Indian public schools. Therefore, the key objectives are to identify the major factors of School Knowledge Management and analyze the impact of KM in secondary education on academic performance, based on the perception of school teachers. Though academic performance was defined in the context of higher education referring to universities, it is also equally relevant in school education. Academic performance in schools is defined as the display of knowledge or skills of students in schools subjects or any expression used to represent students' scholastic achievement (Adediwura and Tayo, 2007). The first objective is to identify the KM practices followed in the Indian context, as the variables of School KM are identified from the past studies conducted in other geographical contexts. Though a few studies were conducted in the past to identify the scope of KM in schools and its variables, a predictive analysis of the impact of these variables on academic performance of students remains neglected except for the study done by Cheng (2012) in Hong Kong secondary schools that focused on knowledge strategies from a process perspective. Besides, the recent studies conducted on School KM focused on strategic outcomes of KM including school learning capacity, KM leadership, Teacher Competencies, School effectiveness in terms of career development, initiatives for implementation of KM and Capitalising School knowledge (Cheng, 2012; Chu 2016a; Chu 2016b; Shih and Tsai, 2016; Cheng, 2017; Supermane and Tahir, 2018; Hallinger, Liu and Piyaman, 2019), ignoring the impact of KM on academic performance of the students. This study identified the possible processes and enablers of school KM comprehensively involving all the internal dimensions (curriculum standards, teaching process, learning initiatives, collaborative learning, shared culture and leadership support) and its impact on academic performance.

The scope of School KM had only been explored in the Asian context and needs to be researched in European and western context as well. As school education is demanding a rigorous revamp in terms of technology and virtual learning, this study would add value to the implementation of effective KM systems in schools.

\section{Literature Review}

\subsection{Knowledge Management}

Knowledge resources are strategic assets that play a significant role in differentiating an entity from competition through the dynamic process of knowledge creation (Drucker, 1966: Nonaka and Takeuchi 1995). In organizations, knowledge is managed through organizational routines, processes, practices and norms (Davenport and Prusak, 1998). Gartner Group (1998) defined KM as a discipline that promotes an integrated approach to identifying, capturing, evaluating, retrieving, and sharing all of an organization's information assets. The KM processes such as creation, generation or acquisition support the management of explicit knowledge and enhance organizational learning (Firestone and McElroy, 2004; Jain and Moreno, 2015). Lee and Choi (2003) had defined that KM factors include enablers, processes and organizational performance. KM process represent 
basic operations of knowledge, whereas KM enablers are influencing factors that are necessary to provide the infrastructure to increase the efficiency of KM (Lee and Choi, 2003).

In the case of corporate organizations, KM inside and outside the organization's boundaries contributed to the value chain with the purpose of achieving corporate objectives efficiently (Davenport 1994; Nonaka and Takeuchi, 1995; Nonaka and Teece, 2001; Alavi and Leinder, 2001; Drucker 2001; Dalkir, 2005; Chen and Chen, 2006; Magnier-Watanabe and Senoo, 2008; Shakerian, Dehnavi and Shateri, 2016; Lim et al., 2017). KM is also identified to be significant in the public sector contributing to effective policymaking and better service delivery (Cong and Pandya, 2003; Reige and Lindsay, 2006; Pee and Kankanhalli, 2016). Rapidly evolving technology has paved the way for innovations, which also depended on KM in organizations both inter-and intraorganizationally (Obeidat, Al-Suradi and Tarhini, 2016). Sallis and Jones (2002) explained how educational institutions can benefit from KM as the business of education itself is knowledge. Education again can be categorized from primary education to higher education and universities, where the KM practices vary with differences on the institutional objectives. Schools as learning organizations were focused seriously because the ideology reoriented the nature of learning and learning outcomes creating a broader impact on society (Giles and Hargreaves, 2006). Though the idea of schools becoming a learning organization is interesting, schools still have many obstacles such as improving internal communication, regular review of learning experiences, better leadership, addressing the local environment and considering the interests of clients and other stakeholders (Karsten, Voncken and Voorthuis, 2000; Fauske and Raybould, 2005; Tahir et al., 2013).This requires the implementation of systematic KM process to streamline the learning initiatives.

\section{$2.2 \mathrm{KM}$ in Schools}

KM systems were implemented widely in corporate organizations since the late 1990s, but research on the integration of knowledge practices in schools are few (Fullan, 2002; Lee, Lu, Yang, 2010; Chu, 2016b; Supermane and Tahir, 2018).The role of internet technology and the increasing digitization have increased the complexity of educational practices which made it critical for school organizations to introduce KM (McKenzie, Truc and van Winkelen, 2001; Richard, 2001; Kuo, 2003). School KM was well defined by Cheng (2015) as a set of relatively new organizational activities that make use of knowledge as an important resource to improve organizational behaviours, decisions, student learning, teaching processes and collegial relationships that enable schools to improve their overall performance. $\mathrm{KM}$ and conversion process between tacit and explicit knowledge illustrated by SECI model (Nonaka and Takeuchi, 1995) which can be applied in any industry is also relevant in managing the schools. SECI model explains a set of processes such as Socialization, Externalization, Combination and Internalization, which results in effective creation, transfer, storage and application of organizational knowledge. Joia (2002) conducted study in schools using the SECI to evaluate the knowledge creation and sharing process and their impact on skill development of teachers. The Socialization process enables the creation of new tacit knowledge when internalized knowledge is shared. The externalization helps in converting this tacit knowledge to explicit knowledge through practices of lesson plans, classroom sessions and other learning activities. The documentation of these activities helps in the codification of knowledge and the knowledge embedded in the structural capital get internalized in the next phase. Several factors enable the effectiveness of KM in schools such as leadership support, sharing culture, competency of people and technology infrastructure (Rodrigues and Pai, 2005). Leung (2010) found that leadership and change management, strategies and goals, organizational learning, technical support, school culture and trust among teachers are the critical factors affecting KM in the school context. School leaders need to know their school's overall intellectual capital, not only on an individual level, but about the whole school structure and culture and take strategic initiatives to improve the academic performance (Hargreaves, 1999; Tahir et al., 2013; Chu,2016b). It is the responsibility of the leader( principal) to assess the staff, existing practices and infrastructure before initiating KM in schools (Chu, 2016a; Chu, Wang and Yuen, 2011). Newman (2000) explains five components as function of 'school capacity', namely, individual teacher knowledge, skills and dispositions, professional learning community (across teachers), program coherence, technical resources, and principal leadership.

Teachers are knowledge workers and can therefore act as sources of knowledge creation. The existing pedagogy involves a tinkering process where teachers undergo a 'trial and error' activity in their classroom. When such tinkering becomes more systematic, more collective and explicitly managed, it is transformed into knowledge creation and generates learning, even if successful knowledge transfer does not occur (Hargreaves, 1999). Another important phase of KM in school is knowledge sharing, as it can transform the teaching profession in intellectual and moral aspects also in developing a collegial knowledge culture in schools (Fullan, 2002; Chu, 
2016b). This is possible only if organizations have a sharing culture that promotes a collaborative environment for discussions. However, this is not prevalent in many schools (Harris, 2001) and management intervention and supportive leadership may be necessary to enable mutual support among the teachers to learn and grow. A collaborative environment for teachers to share ideas and provide mutual support offers the potential benefits of raising teacher confidence, facilitating teacher learning and embedding improvements in professional practice within the classroom (Rhodes and Beneicke, 2002). But it is the sole responsibility of teachers to ensure their teaching effectiveness. Teachers should regularly update themselves with new information and enhance their knowledge. Benefits of KM based on teachers perceptions include facilitating students' learning, understanding students capability, gaining practical knowledge, facilitating teacher collaboration for knowledge creation, nurturing a sharing culture in the school, creating new knowledge and keeping abreast of new knowledge, compiling expertise from teachers and better document management (Azman, 2003; Chu, 2016). Rodriguez and Pai Model (2005) on KM strategies for school education include eight variables namely: Leadership and Support, Technology and Infrastructure, Knowledge Creation, Acquisition and Learning, Dissemination and Transfer, Application and Exploitation, People Competency and Sharing Culture. These eight dimensions include most typical KM enablers and processes. Chu, Wang and Yuen (2011) used this model to explore the factors of KM implementation in a secondary school in their qualitative study. Compared to the private sector, public sector organizations are challenged by the knowledge hoarding generated by the conventional mind-set of people and hence need to focus on improving organizational culture that supports knowledge creation (Joshi, Jamal and Chawla, 2013; Jain and Jeppesen; 2013). KM in public schools also faces the same challenges. But there are several benefits that public sector organizations can acquire through ideal KM practices which can also be effectively applied in education. Some of them are clearly defined by Cheng (2015) such as improving organizational behaviours, decisions, better pedagogy, student learning, etc. Overall challenges that are faced by public schools in developing KM include the technological limitations in school systems, the lack of time for teachers to facilitate outside the classroom, and budgetary constraints (Edge, 2005).

Cheng (2012) had already identified knowledge retrieval, utilization and sharing as the predictive factors for individual learning capacity and school learning capacity. Applying KM makes the KM processes such as creation, sharing and application create a sound foundation for academic performance of students and performance in other areas and for the school's development as a whole (Zwain, Lim and Othman, 2012; Cheng, 2013; Shih and Tsai, 2016). Shih and Tsai (2016) combined both processes and enablers as predictors of School KM. But the impact of KM on academic performance was not empirically tested in this study; instead, it focused on the strategic outcome such as perceived school effectiveness of career. Cheng (2017) further explored how KM can generate human capital in school organizations. Supermane and Tahir (2018) researched how KM can improve teaching quality and learning initiatives. This study is indeed a shift from studies focusing on strategic outcomes to immediate outcomes that can significantly contribute to strategic goals. Another immediate impact of KM that was not empirically tested is academic performance. This was rather considered to be obvious to achieve, but it is important to explore the effect of the KM processes and enablers on academic performance as it would help the school organizations to improve on every level of KM initiative and make changes wherever required.

Adediwura and Tayo (2007) defined academic performance in schools as the display of knowledge or skills of students in schools' subjects or any expression used to represent students' scholastic achievement. Academic performances are usually assessed or rated based on examinations scores/report card grades (Adediwura and Tayo, 2007; Brackett et al., 2012). The attributes 'grades' and 'attendance' are relevant for predicting the end of the year academic outcomes of student performance and these grades are based on analysis of discipline and elaborate written communication which was contemporarily improvised include mathematical and aptitude skills (Marks and Louis,1997; Luiselli et al., 2005; Fernandes et al., 2012). Though grades are used to objectively evaluate academic performance, the subjective evaluation of the teachers are also well correlated with this objectivity. Meissel, Meyer, Yao and Rubie-Davies (2017) explored the relations between standardized tests and teachers' judgments about student scholastic achievement and identified a strong correlation between the two measures.

\section{Methodology}

The study is empirical and the data is collected from the secondary school teachers to analyze their perceptions of existing KM practices. The study is done with the support of a structured questionnaire which included fivepoint Likert scale questions based on KM variables identified from past literature. The variables were identified from the qualitative research done by Chu, Wang and Yuen (2011) on KM in a secondary school at Hong Kong 
using the Rodriques and Pai Model. The authors of this study had indicated the scope of further survey-based studies on these KM variables in a different context for better clarity of learning outcomes in schools. Moreover, the model has comprehensively identified all the major KM processes and enablers that are significant to secondary education from teacher's perspective. Some questions and statements were adapted from qualitative studies of Cheng (2015) on KM in school education. Table 1 illustrates the variables formulated from existing works of literature on teaching and education.

Table 1: Variables of School Knowledge Management

\begin{tabular}{lrl}
\hline Item & Variables \\
\hline 2 & Curriculum standards and quality (Chu, 2016b) \\
3 & Principal's Coordination of activities (Harris,2001) \\
4 & Use of Information and Communication Technology (ICT) (Haughey, 2006). \\
5 & Freedom to develop lesson plans (Newmann,2000) \\
6 & Regular update of subject knowledge (Tahir et al.,2013;Petrides and Nodines, 2003) \\
7 & Seminars, Workshops and Trainings (Tahir et al., 2013) \\
8 & Support of fellow teachers (Rhodes and Beneicke, 2002; Azman, 2003) \\
9 & Innovative methods in teaching (Haughey,2006) \\
10 & Regular feedback from students (Chu, 2016). \\
11 & Collaborative environment for open discussion (Dixon, 2000; Paraponaris et al., 2015; Chu, 2016a). \\
12 & Access to alumni (Chu, 2016b). \\
13 & Technology oriented evaluation and reporting (Haughey, 2006; Chu, 2016). \\
14 & Evaluation of teaching methodology (Petrides and Nodines, 2003) \\
15 & Teacher's self-satisfaction on their teaching skills(Newmann,2000) \\
16 & Support for new teachers (Rhodes and Beneicke, 2002). \\
17 & Free Internet access (Paraponaris et al., 2015) \\
18 & Data-driven decisions and interventions by principal (Haughey,2006) \\
19 & Support of administrative staff (Chu, 2016). \\
20 & Appraisal of student suggestions (Paraponaris et al., 2015) \\
21 & Principal's support for teachers (Hargreaves, 1999; Tahir et al., 2013). \\
&
\end{tabular}

The scope of the study is limited to the secondary school teachers of government schools in the Kasargod district of Kerala state. Kerala is the southern state of India with high Human Development Index (HDI) and good literacy rate compared to other Indian states. The district has a total of 90 Government Higher Secondary Schools with an average of 7 secondary school teachers in each school. The list of these 90 schools were taken from the official website of Kerala Government. Out of these 40 schools are rural (44\%), 32 schools semi-urban (35\%) and 18 schools are urban (21\%). But out of 40 rural schools, 10 schools were excluded in the study as they are geographically located in remote areas and are not easily accessible for the researchers. A proportionate stratified random sampling method is used where 28 schools were identified as the stratified sample (13 rural schools, 11 semi-urban schools and 4 urban schools). The random number generator is used in the list of the schools to create the final list for the survey. But due to practical difficulties of getting official approval, we could collect data from 18 schools only. Therefore, a stratified random sample of 175 respondents from 18 Government Schools of Kasargod district constituted the study. The study is purely based on the perception of school teachers on School KM. The researcher personally visited the schools, distributed and collected the questionnaires from teachers.

\section{Data Analysis}

It was important to identify the key factors of KM in secondary education based on the interrelated variables and therefore, factor analysis was conducted using SPSS v.20. A Principal Component Analysis with varimax rotation was adopted. Exploratory factor analysis requires certain basic assumptions to be satisfied namely multivariate normality and sampling adequacy (Bryant and Yarnold, 1995; George and Mallery, 1999; Lattin, Carroll and Green, 2003). The KMO Bartlett test includes Bartlett test of sphericity that measures the multivariate normality of variables in addition to analyzing whether the correlation matrix is an identity matrix (i.e., a spherical set of multivariate data) (George and Mallery, 1999; Lattin, Carroll and Green, 2003). The Kaiser- 
Meyer-Olkin (KMO) test can measure whether the sample size is adequate for conducting factor analysis (George and Mallery, 1999).

The KMO measure of sample adequacy is .654 which is greater than the acceptable threshold of 0.5 . Therefore, the sample is adequate for exploratory factor analysis (Table 2). As the Bartlett's Test of sphericity is highly significant $(p<.05)$, the correlation matrix is identical and thus suitable for factor analysis.

Table 2: KMO and Bartlett's Test

\begin{tabular}{lll}
$\begin{array}{l}\text { Kaiser-Meyer-Olkin Measure of Sampling } \\
\text { Adequacy. }\end{array}$ & \\
& Approx. Chi-Square & 0.654 \\
Bartlett's Test of & df & 210 \\
Sphericity & Sig. & 0 \\
\hline
\end{tabular}

Chu, Wang and Yuen (2011) explored the eight KM variables proposed by Rodriguez and Pai (2005) in their qualitative study on a secondary School in Hong Kong. The sub-variables which were further identified (Table 1) from literatures were analyzed in Indian schools and therefore it is important to explore the key factors in the new context. The Exploratory Factor Analysis (Table 3) using Principal Component Analysis with varimax rotation also extracted eight factors, which were conceptually identical to variables of Rodriguez and Pai's (2005) model.

Table 3: Exploratory Factor Analysis

\begin{tabular}{|c|c|c|c|c|c|c|}
\hline Item & Factor & Variables included in the factor & $\begin{array}{l}\text { Factor } \\
\text { Loading }\end{array}$ & $\begin{array}{l}\text { Eigen } \\
\text { Value }\end{array}$ & $\begin{array}{l}\text { Variance } \\
\text { explained \% } \\
\end{array}$ & $\begin{array}{l}\text { Cumulative } \\
\text { variance } \\
\text { explained \% }\end{array}$ \\
\hline 1 & \multirow{4}{*}{$\begin{array}{l}\text { Acquisition } \\
\text { and learning }\end{array}$} & Innovative method of teaching & 0.771 & \multirow[b]{4}{*}{4.669} & \multirow[b]{4}{*}{11.304} & \multirow[b]{4}{*}{11.304} \\
\hline 2 & & Support for new teachers & 0.756 & & & \\
\hline 3 & & Freedom to develop lesson plans & 0.669 & & & \\
\hline 4 & & $\begin{array}{l}\text { Collaborative environment for } \\
\text { open discussion }\end{array}$ & 0.641 & & & \\
\hline 5 & \multirow{2}{*}{$\begin{array}{l}\text { Dissemination } \\
\text { and Transfer }\end{array}$} & Support of fellow teachers & 0.955 & \multirow[b]{2}{*}{2.488} & \multirow[b]{2}{*}{10.603} & \multirow[b]{2}{*}{21.907} \\
\hline 6 & & Regular feedback from students & 0.899 & & & \\
\hline 7 & \multirow[b]{3}{*}{$\begin{array}{l}\text { Leadership } \\
\text { and Support }\end{array}$} & Principal's support for teachers & 0.943 & \multirow[b]{3}{*}{2.044} & \multirow[b]{3}{*}{10.453} & \multirow[b]{3}{*}{32.36} \\
\hline 8 & & $\begin{array}{l}\text { Principal's Coordination of } \\
\text { activities }\end{array}$ & 0.921 & & & \\
\hline 9 & & $\begin{array}{l}\text { Management and leadership } \\
\text { support }\end{array}$ & 0.506 & & & \\
\hline 10 & \multirow{3}{*}{$\begin{array}{l}\text { Application } \\
\text { and } \\
\text { Exploitation }\end{array}$} & Appraisal of student suggestions & 0.764 & \multirow[b]{3}{*}{1.503} & \multirow[b]{3}{*}{10.111} & \multirow[b]{3}{*}{42.472} \\
\hline 11 & & Curriculum standards and quality & 0.682 & & & \\
\hline 12 & & $\begin{array}{l}\text { Evaluation of teaching } \\
\text { methodology }\end{array}$ & 0.662 & & & \\
\hline 13 & \multirow{3}{*}{$\begin{array}{l}\text { Knowledge } \\
\text { Creation }\end{array}$} & Use of ICT & 0.803 & \multirow[b]{3}{*}{1.431} & \multirow[b]{3}{*}{8.754} & \multirow[b]{3}{*}{51.226} \\
\hline 14 & & $\begin{array}{l}\text { Regular update of subject } \\
\text { knowledge }\end{array}$ & 0.747 & & & \\
\hline 15 & & Seminars, workshops and Trainings & 0.508 & & & \\
\hline 16 & \multirow{2}{*}{$\begin{array}{l}\text { Sharing } \\
\text { Culture }\end{array}$} & Access to alumni & 0.839 & \multirow[b]{2}{*}{1.237} & \multirow[b]{2}{*}{8.202} & \multirow[b]{2}{*}{59.428} \\
\hline 17 & & Support of administrative staff & 0.837 & & & \\
\hline 18 & \multirow{2}{*}{$\begin{array}{l}\text { Technology } \\
\text { Infrastructure }\end{array}$} & $\begin{array}{l}\text { Data driven decisions and } \\
\text { interventions by principal }\end{array}$ & 0.764 & \multirow[b]{2}{*}{1.153} & \multirow[b]{2}{*}{7.594} & \multirow[b]{2}{*}{67.021} \\
\hline 19 & & Free internet access & 0.725 & & & \\
\hline 20 & \multirow{2}{*}{$\begin{array}{l}\text { People } \\
\text { Competency }\end{array}$} & $\begin{array}{l}\text { Technology oriented evaluation } \\
\text { and reporting }\end{array}$ & 0.692 & & \multirow[b]{2}{*}{6.974} & \multirow[b]{2}{*}{73.996} \\
\hline 21 & & $\begin{array}{l}\text { Teacher's self-satisfaction on their } \\
\text { teaching skills }\end{array}$ & 0.498 & 1.013 & & \\
\hline
\end{tabular}


The eight factors, namely: Acquisition and Learning, Dissemination and Transfer, Leadership and Support, Application and Exploitation, Knowledge Creation, Sharing Culture, Technology Infrastructure, People Competency together contribute 73.996 percent of cumulative variance to the study. The remaining 26 percent are contributed by other factors.

A binary logistic regression was applied to estimate the impact of KM in Government Schools on academic performance of the students. The academic performance of students is the dependent variable and the independent metric variables are Acquisition and Learning, Dissemination and Transfer, Leadership and Support, Application and Exploitation, Knowledge Creation, Sharing Culture, Technology Infrastructure, People Competency. The hypotheses for the logistic regression can be stated as follows:

Ho: The School KM factors do not have a significant impact on Academic Performance.

$H_{1}$ : The School KM factors have a significant impact on Academic Performance.

The binary logistic regression model is as follows: $\operatorname{Ln}[p /(1-p)]=\alpha+\beta x+\varepsilon$, where $p$ is the probability that the event occurs. The $p /(1-p)$ is the odds ratio which is the ratio of the probability of an event occurring to the probability of the event not happening. The $\alpha$ is the $Y$ intercept; $x$ is a set of predictors; ßs are regression coefficients.

A 5-point Likert-scale with questions ranging from strongly disagree (1) to strongly agree (5), was used to measure the opinion of teachers on the sub-variables (Table 1) of KM in schools. The reliability of the questionnaire is tested for the KM Enablers and KM Processes with a sample of 30 respondents and the Cronbach's alpha values are .813 and .794 respectively. Since the reliability is $81 \%$ and $79 \%$ respectively, which is above the acceptance level of $70 \%$, the questionnaire was considered reliable.

The maximum likelihood estimation procedure is used to estimate the binary logistic regression model. Since the $p$-value is $0.007(<.05)$, it proves that overall model was statistically significant. This indicated that the full model was a better predictor than a model with the intercept alone. The model is statistically reliable in distinguishing KM practices that can create an improvement in academic performance and those that cannot. It is required to test the basic assumption of evaluating the goodness-of-fit of the model and the Hosmer Lemeshow Test (Table 4) is used for it (Hosmer and Lemeshow, 2000).

The resulting test statistic was not statistically significant ( $\chi 2$ value 14.401 and, $p$-value 0.072 ); therefore, the null hypothesis ( $H_{0}$ : There is no difference between the observed and the model predicted values on academic performance) was rejected. This implied that the model fits the data well at a statistically, acceptable level.

Table 4: Hosmer and Lemeshow test

\begin{tabular}{cccc} 
Step & Chi-square & df & Sig. \\
\hline 1 & 14.401 & 8 & 0.072 \\
\hline
\end{tabular}

Another test statistic (Table 5), the Nagelkerke $\mathrm{R}^{2}$, indicates how useful the explanatory variables were in predicting the response variable. The Nagelkerke $R^{2}$, which varies from 0 to 1 , was 0.256 , indicating the model was useful in predicting the impact of KM practices on academic performance.

Table 5: Model Summary

\begin{tabular}{cccc} 
Step & -2 Log likelihood & $\begin{array}{c}\text { Cox \& Snell } \\
\text { R Square }\end{array}$ & $\begin{array}{c}\text { Nagelkerke R } \\
\text { Square }\end{array}$ \\
\hline 1 & 81.361 & 0.113 & 0.256 \\
\hline
\end{tabular}

The logistic regression coefficient, standard error, Wald's chi-square, p-value and odds ratio for each of the predictors are shown in Table 6 . The Wald and associated $p$-value is used to test the statistical significance of each coefficient $(\beta)$ in the model (Field, 2007), which represent the KM variable. 
Table 6: Logistic Regression

\begin{tabular}{lcccccc}
\hline & B & S.E. & Wald & df & Sig. & $\operatorname{Exp}(\mathrm{B})$ \\
\hline Acquisition and learning & -0.783 & 0.573 & 1.867 & 1 & 0.172 & 0.457 \\
Dissemination and transfer & -0.599 & 0.739 & 0.657 & 1 & 0.418 & 0.55 \\
Leadership and support & -0.097 & 0.947 & 0.01 & 1 & 0.919 & 0.908 \\
Application and Exploitation & -1.422 & 0.627 & 5.144 & 1 & 0.023 & 0.241 \\
Knowledge creation* & 0.024 & 0.776 & 0.001 & 1 & 0.975 & 1.025 \\
Shared culture & -0.818 & 0.443 & 3.404 & 1 & 0.065 & 0.441 \\
Technology infrastructure* & 1.442 & 0.876 & 2.708 & 1 & 0.1 & 4.23 \\
People Competency* & 0.005 & 0.145 & 0.001 & 1 & 0.973 & 1.005 \\
Constant & 5.396 & 3.734 & 2.088 & 1 & 0.149 & 220.462 \\
\hline
\end{tabular}

Note: '*" indicates variables with odds ratio greater than 1

The results indicate that the application and exploitation of knowledge is significant to academic performance in schools ( $p$-value .023<.05). Hence the $H_{0}$ is rejected for this KM process. Other factors are currently not significant in improving the academic performance of students. This result is purely based on the perception of school teachers. Considering the Odds ratio (Exp (B), in Table 6 it is observed that the Exp (B) of Knowledge Creation (1.025), Technology Infrastructure (4.230) and People Competency (1.005) are greater than 1 and it indicates that a slight increase in value of these variables can result in improving academic performance by 1.025 times, 4.23 times and 1 time respectively. This indicates that these KM practices can probably improve the academic performances in public schools to a greater extend compared to other parameters of KM. Notably, the technology infrastructure plays a significant role in improving the KM practices for better academic performance of students.

\section{Discussions}

The existing studies on KM in education reveals many factors that are significant in improving the academic quality such as leadership support, collegial relationship among the teachers, organizational behaviour, teaching methodology and student learning (Chu, Wang and Yuen, 2011; Cheng, 2015; Chu, 2016b; Cheng, 2017). But this study has identified the processes of KM that enhance learning along with the enablers that significantly contribute in the execution of the knowledge processes. Out of the eight factors Acquisition and Learning, Knowledge Creation, Dissemination and Transfer, Application and Exploitation are the KM processes (Nonaka and Takeuchi, 1995; Cheng, 2012). Leadership and Support, Sharing Culture, People Competency and Technology Infrastructure are the knowledge enablers (Chu, Wang and Yuen, 2011). The knowledge facilitators in organizations that positively enable the KM processes such as Organisational Culture, Organisational structure, Technology Infrastructure, Human Resource Management processes, etc. are also referred to as knowledge enablers (Lee and Choi, 2003). Among the KM factors, Acquisition and Learning process involve the methods used by teachers in searching knowledge and learning; Knowledge Creation involve workplace knowledge creation through ICT and initiatives to develop new knowledge; Dissemination and Transfer refers to facilitations of transferring knowledge and information within the organization; Application and Exploitation involves employee's attitudes and requirements for applying knowledge and putting it into practice (Rodriques and Pai, 2005; Chu, Wang and Yuen, 2011). Table 3 clearly illustrates the various School KM activities that are initiated for the above processes. These processes are important in the SECl model for KM in Schools. When Acquisition and Learning contribute to the process of socialisation, the externalisation of knowledge is initiated by Creation, Dissemination and Transfer. Application and Exploitation contribute to Codification and Internalization of Knowledge.

It was identified from the analysis that the Technology Infrastructure plays a significant role in improving the academic performance through KM. The existing infrastructure is not found to be satisfied as the relationship of Technology Infrastructure to academic performance is not significant. Although the schools are equipped with internet access and Use of ICT, the extent to which they are being utilized to improve the academic quality is not sufficient. The studies conducted in other Asian countries like China, Malaysia, Taiwan and Japan clearly states the contribution of technology in education, as the development of internet technology has increased the scope 
of KM in education (Richard, 2001; David, 1999; Kuo, 2003; McKenzie, Truc and van Winkelen, 2001; Chu, Wang and Yuen, 2011; Cheng 2017). This is a challenge to public schools compared to private schools in India.

People's Competency is an inevitable factor in education. Though the recruitment of teachers in public schools is conducted systematically, a consistent development of skill is lacking as teaching is always limited to a regular tinkering process (Hargreaves, 1999). In this study the competency is measured by analysing how effectively the teachers use technology for evaluation and to the level of self-satisfaction they have on their teaching skills. Teachers should be well aware of their effectiveness and should always strive to develop their teaching skill (Chu, 2016). Personal strategies of teachers also tend to influence the knowledge culture within schools. The personal strategies can manipulate the way people seek and tolerate new knowledge, and how ideas are valued and used (Hamid, 2008). Higher levels of personal knowledge strategies are also likely to result in a stronger belief in the quality process of decision making in schools and teachers are required to develop their learning competency in order to acquire subject knowledge and pedagogical knowledge when implementing the new curriculum. (Cheng, 2012; 2015).

When the teachers effectively use the technology infrastructure to update the developments, the regular tinkering process can be made more creative, systematic and explicit resulting in Knowledge Creation (Hargreaves, 1999). This can be enhanced through participation in seminars, workshops and conferences (Tahir et al., 2013). The study reveals that knowledge creation process can definitely contribute to academic performance of students. Knowledge creation in this study actually refers to creation of new knowledge through learning initiatives and use of information and communication technology for regular updates.

\section{Conclusion}

As far as the economic and social growth of a nation is concerned, the opportunity and quality of secondary education need to be focused as it contributes significantly to the social, cultural, moral and technological orientation of an individual. As such orientation can be greatly brought through effective KM practices; this study reveals an eye-opening reality of the impact of KM practices on academic performance in public schools in India. Some of the significant contributions of the study include:

1. Out of the School KM factors, Acquisition and Learning, Knowledge Creation, Dissemination and Transfer, Application and Exploitation are the KM processes, and Leadership and Support, Sharing Culture, People Competency and Technology Infrastructure are the KM enablers. Although these variables were explored in other geographical contexts, it was not explored in the Indian context so far. Except for the study conducted by Shih and Tsai (2016) other recent studies focused on one or few of $\mathrm{KM}$ processes or enablers. But this study comprehensively identified all major factors of school KM, both processes and enablers.

2. Although the public schools are equipped with internet access and Use of ICT, the extent to which they are being utilized to improve the academic quality is not sufficient. Knowledge Strategies that can effectively utilize the technology infrastructure through KM systems in schools are mandate for better academic outcome.

3. Apart from the schemes implemented by national and international agencies to improve the competencies and skills of teachers, personal knowledge strategies should be initiated by teachers for self-evaluation and individual learning to increase their competency.

4. When the teachers effectively use the technology infrastructure to update the developments, the regular tinkering process can be made more creative, systematic and explicit resulting in Knowledge Creation, contributing to academic development of students.

5. Academic performance, being mentioned as the primary outcome of School KM has not been empirically tested from a School KM perspective earlier. The knowledge creation, technology infrastructure and teachers competency being identified as KM factors that can influence the Academic Performance, the schools can initiate policies and methods to improve these vital factors.

It was interesting to note that the key KM factors that predicted higher impact on academic performances were enablers such as technology infrastructure and people competency. The knowledge creation process needs to be revamped with dissemination and application of knowledge, which would undoubtedly enhance the academic quality and school effectiveness (Shih and Tsai, 2016). Moreover, knowledge creation can pave way to innovation and creativity. It is high time to remove the dilemma of what is important and how to prioritize based on the changing scenario of education. Though Fullan (2002) has stated that sustainability depends on system wide efforts at the level of schools, communities and districts, as well as radically more enlightened 
policies and incentives at the level of the state and the state took up various initiatives to this regard, the outcome is yet to materialize.

The study is limited to the government schools of Kasargod district in Kerala state. Kerala is an Indian state with high Human Development Index (HDI), where education is given prime importance compared to other states of India. Therefore, the sample could be an ideal representative for the study, though the results could not be generalized fully in Indian context. But the curriculum and practices of education followed in all the states are similar and hence not fully limited in scope. Future studies can better focus on other districts of the country on the same parameters. From an international perspective the findings of this study can be generalised in Asian context, as this study was inspired by School KM conducted in Iraq, China, Thailand and Malaysia (Zwain, Lim and Othman, 2012; Cheng, 2013; Chu, 2016; Shih and Tsai, 2016; Supermane and Tahir, 2018) and further tested in Indian context. Future researches need to explore the scope of KM processes and enablers in European and western contexts. Besides the study is limited to the subjective evaluation of teachers on KM practices existing in secondary education and teachers are the best respondents for this study, as they are the key knowledge workers directly involved in School KM and also in the evaluation of academic performance of students. This study also limits to identifying the impact of KM on academic performance. There are several other aspects of school education such as pedagogy, teacher skill development and leadership which can be explored based on KM practices. Besides, feedback from other stakeholders such as students' parents and the administrative authorities in education development on improving the KM practices can also enhance the future research.

The future studies can be extended to the perception of other stakeholders of schools including students, parents, administrators and the public. Approach of school KM also need to be researched in the European and western contexts. Practically school KM factors can be used for the implementation Knowledge Management Systems (KMS) in school in future to streamline all the knowledge activities effectively. This is highly relevant in the context where teaching and learning are becoming virtual and more technology orient.

\section{References}

Adediwura, A.A. and Tayo, B., 2007. Perception of teacher's knowledge, attitude and teaching skills as a predictor of academic performance in Nigerian secondary schools. Educational Research and Reviews, 2(7), pp.165-171. https://doi.org/10.5897/ERR.9000250

Alavi, M. and Leidner, D.E., 2001. Knowledge management and knowledge management systems: Conceptual foundations and research issues. MIS Quarterly, 25(1), pp.107-136.

Azman, S., 2003. Teacher's awareness in implementing [MO1] knowledge management practices: a case study towards teachers at SMK Tunku Abdul Rahman Putra Kulai (Unpublished Master Education project paper). Universiti Teknologi Malaysia.

Brackett, M.A., Rivers, S.E., Reyes, M.R. and Salovey, P., 2012. Enhancing academic performance and social and emotional competence with the RULER feeling words curriculum. Learning and Individual Differences, 22(2), pp.218-224. https://doi.org/10.1016/j.lindif.2010.10.002

Bryant, F. B and Yarnold, P. R., 1995. Principal-components analysis and exploratory and confirmatory factor analysis. In L. G. Grimm and P. R. Yarnold (Eds.), Reading and understanding multivariate statistics. Washington, DC: American Psychological Association, pp. 99-136

Chen, C.H. and Chen, Y.H., 2006. Effects of knowledge management implementation in hospitals: An exploratory study in Taiwan. International Journal of Knowledge Management (IJKM), 2(3), pp.1-20. https://doi.org/10.4018/jkm.2006070101.

Cheng E.C., 2015.A knowledge management model for school development. Knowledge Management for School Education. Springer Briefs in Education. Singapore: Springer, pp.71-83. https://doi.org/10.1007/978-981-287-233-3_7

Cheng, E.C., 2012. Knowledge strategies for enhancing school learning capacity. International Journal of Educational Management, 26(6), pp.577-592. https://doi.org/10.1108/09513541211251406

Cheng, E.C., 2013. Applying knowledge management for school strategic planning. KEDI Journal of Educational Policy, 10(2), pp. 339-356.

Cheng, E.C., 2017. Knowledge management strategies for capitalizing on school knowledge. VINE Journal of Information and Knowledge Management Systems, 47(1), pp.94-109. https://doi.org/10.1108/VJIKMS-08-2016-0045

Chu, K.W., 2016a. Beginning a journey of knowledge management in a secondary school. Journal of Knowledge Management, 20(2), pp.364-385. https://doi.org/10.1108/JKM-04-2015-0155

Chu, K.W., 2016b. Leading knowledge management in a secondary school. Journal of Knowledge Management, 20(5), pp.1104-1147. https://doi.org/10.1108/JKM-10-2015-0390

Chu, K.W., Wang, M. and Yuen, A.H., 2011. Implementing knowledge management in the school environment: teachers' perception. Knowledge Management \& E-Learning: an International Journal, 3(2), pp.139-152. https://doi.org/10.34105/j.kmel.2011.03.013

Cong, X. and Pandya, K.V., 2003. Issues of knowledge management in the public sector. Electronic Journal of Knowledge Management, 1(2), pp.25-33. 
Dalkir, K., 2005. The knowledge management cycle. Knowledge management in theory and practice. Oxford: Elsevier, pp.25-46.

Davenport, T.H. and Prusak, L., 2000. Working knowledge: how organizations manage what they know. Ubiquity, 2000(August), p.6.

Dixon, N.M., 2000. Common knowledge: How companies thrive by sharing what they know. Boston: Harvard Business School Press.

Drucker, P.F., 1966. The effective executive, New York, NY: Harper Colophon.

Drucker, P.F., 2001. Knowledge work and knowledge society: the social transformations of this century. London: British Library.

Edge, K., 2005. Powerful public sector knowledge management: a school district example. Journal of Knowledge Management, 9(6), pp.42-52. https://doi.org/10.1108/13673270510629954

Edvinsson, L. and Malone, M., 1997. Intellectual capital: realizing your company's true value by finding its hidden brainpower. New York: Harper Business.

Fauske, J.R. and Raybould, R., 2005. Organizational learning theory in schools. Journal of Educational Administration, 43(1), pp.22-40. https://doi.org/10.1108/09578230510577272.

Fernandes, E., Holanda, M., Victorino, M., Borges, V., Carvalho, R. and Van Erven, G., 2019. Educational data mining: Predictive analysis of the academic performance of public school students in the capital of Brazil. Journal of Business Research, 94, pp.335-343. https://doi.org/10.1016/i.jbusres.2018.02.012

Field, A., 2013. Discovering statistics using IBM SPSS statistics. London: Sage.

Firestone, J.M. and McElroy, M.W., 2004. Organizational learning and knowledge management: the relationship. The Learning Organization, 11(2), pp. 177-184. https://doi.org/10.1108/09696470410521628

Fullan, M. and Fullan, M.G., 1993. Change forces: Probing the depths of educational reform (Vol. 10). London: Routledge Falmer

Fullan, M., 2002. The role of leadership in the promotion of knowledge management in schools. Teachers and Teaching, 8(3), pp.409-419. https://doi.org/10.1080/135406002100000530

George, D. and Mallery, P., 1999. SPSS for Windows step by step: a simple guide and reference Needham Heights, MA: Allyn and Bacon Co.

Giles, C. and Hargreaves, A., 2006. The sustainability of innovative schools as learning organizations and professional learning communities during standardized reform. Educational Administration Quarterly, 42(1), pp.124-156. https://doi.org/10.1177\%2F0013161X05278189

Hallinger, P., Liu, S. and Piyaman, P., 2019. Does principal leadership make a difference in teacher professional learning? A comparative study China and Thailand. Compare: A Journal of Comparative and International Education, 49(3), pp.341-357. https://doi.org/10.1080/03057925.2017.1407237

Hamid, J.A., 2008. Knowledge strategies of school administrators and teachers. International Journal of Educational Management, 22(3), pp. 259-268. https://doi.org/10.1108/09513540810861892.

Hargreaves, D.H., 1999. The knowledge-creating school. British Journal of Educational Studies, 47(2), pp.122-144. https://doi.org/10.1111/1467-8527.00107.

Harris, A., 2001. Building the capacity for school improvement. School Leadership \& Management, 21(3), pp.261-270. https://doi.org/10.1080/13632430120074419

Haughey, M., 2006. The impact of computers on the work of the principal: Changing discourses on talk, leadership and professionalism. School Leadership and Management, 26(1), pp.23-36. https://doi.org/10.1080/13634230500492897.

Hosmer, D.W. and Lemeshow, S., 2000. Applied logistic regression. New York: John Wiley \& Sons.

Jain, A.K. and Jeppesen, H.J., 2013. Knowledge management practices in a public sector organisation: the role of leaders' cognitive styles. Journal of Knowledge Management, 17(3), pp. 347-362. https://doi.org/10.1108/JKM-11-2012-0358

Jain, A.K. and Moreno, A., 2015. Organizational learning, knowledge management practices and firm's performance. The Learning Organization, 22(1), pp. 14-39. https://doi.org/10.1108/TLO-05-2013-0024

Joia, L.A., 2002. Assessing unqualified in-service teacher training in Brazil using knowledge management theory: a case study. Journal of Knowledge Management, 6(1), pp. 74-86. https://doi.org/10.1108/13673270210417718.

Joshi, H., Farooquie, J.A. and Chawla, D., 2016. Knowledge management practices in Indian organizations-A sectoral comparison. Vision, 20(3), pp.211-223. https://doi.org/10.1177\%2F0972262916651534

Karsten, S., Voncken, E. and Voorthuis, M., 2000. Dutch primary schools and the concept of the learning organization. The Learning Organization, 7(3), pp.145-156. https://doi.org/10.1108/09696470010335863

Kuo, Y.F., 2003. A study on service quality of virtual community websites. Total Quality Management \& Business Excellence, 14(4), pp.461-473. https://doi.org/10.1080/1478336032000047237a

Lattin, J.M., Carroll, J.D. and Green, P.E., 2003. Analyzing multivariate data (pp. 351-352). Pacific Grove, CA: Thomson Brooks/Cole.

Lee, C.L., Lu, H.P., Yang, C. and Hou, H.T., 2010. A Process-Based Knowledge Management System for Schools: A Case Study in Taiwan. Turkish Online Journal of Educational Technology-TOJET, 9(4), pp.10-21.

Lee, H. and Choi, B., 2003. Knowledge management enablers, processes, and organizational performance: An integrative view and empirical examination. Journal of Management Information Systems, 20(1), pp.179-228. https://doi.org/10.1080/07421222.2003.11045756. 
Leung, C.H., 2010. Critical factors of implementing knowledge management in school environment: A qualitative study in Hong Kong. Research Journal of Information Technology, 2(2), pp.66-80.

Lim, M.K., Tseng, M.L., Tan, K.H. and Bui, T.D., 2017. Knowledge management in sustainable supply chain management: Improving performance through an interpretive structural modelling approach. Journal of Cleaner Production, 162, pp.806-816. https://doi.org/10.1016/j.jclepro.2017.06.056

Louis, K.S., 1998. Reconnecting knowledge utilization and school improvement: Two steps forward, one step back. In: Hargreaves, A. (ed) International handbook of educational change, pp. 1074-1095. Dordrecht: Kluwer Academic.

Luiselli, J.K., Putnam, R.F., Handler, M.W. and Feinberg, A.B., 2005. Whole-school positive behaviour support: effects on student discipline problems and academic performance. Educational Psychology, 25(2-3), pp.183-198. https://doi.org/10.1080/0144341042000301265

Magnier-Watanabe, R. and Senoo, D., 2008. Organizational characteristics as prescriptive factors of knowledge management initiatives. Journal of Knowledge Management, 12(1), pp. 21-36. https://doi.org/10.1108/13673270810852368.

Marks, H.M. and Louis, K.S., 1997. Does teacher empowerment affect the classroom? The implications of teacher empowerment for instructional practice and student academic performance. Educational Evaluation and Policy Analysis, 19(3), pp.245-275. https://doi.org/10.3102\%2F01623737019003245

McKenzie, J., Truc, A. and van Winkelen, C., 2001. Winning commitment for knowledge management initiatives. Journal of Change Management, 2(2), pp.115-127. https://doi.org/10.1080/714042493

Meissel, K., Meyer, F., Yao, E.S. and Rubie-Davies, C.M., 2017. The subjectivity of teacher judgments: Exploring student characteristics that influence teacher judgments of student ability. Teaching and Teacher Education, 65, pp.48-60. https://doi.org/10.1016/i.tate.2017.02.021

Newman, C.S., 2000. Seeds of professional development in pre-service teachers: A study of their dreams and goals. International Journal of Educational Research, 33(2), pp.125-217. https://doi.org/10.1016/S0883-0355(00)00003-3

Nonaka, I. and Takeuchi, H., 1995. The knowledge-creating company: How Japanese companies create the dynamics of innovation. Oxford: Oxford University Press.

Nonaka, I. and Teece, D.J. eds., 2001. Managing industrial knowledge: creation, transfer and utilization. London: Sage .

Obeidat, B.Y., Al-Suradi, M.M. and Tarhini, A., 2016. The impact of knowledge management on innovation. Management Research Review, 39(10), pp. 1214-1238. https://doi.org/10.1108/MRR-09-2015-0214

Paraponaris, C., Sigal, M., Khedhaouria, A. and Jamal, A., 2015. Sourcing knowledge for innovation: knowledge reuse and creation in project teams. Journal of Knowledge Management, 19(5), pp.932-948. https://doi.org/10.1108/JKM-012015-0039

Pee, L.G. and Kankanhalli, A., 2016. Interactions among factors influencing knowledge management in public-sector organizations: A resource-based view. Government Information Quarterly, 33(1), pp.188-199. https://doi.org/10.1016/i.giq.2015.06.002

Petrides, L.A. and Nodine, T.R., 2003. Knowledge management in education: defining the landscape. [online]. Available at: https://eric.ed.gov/?id=ED477349 [Accessed 16 August 2019]

Polanyi, M. and Knowledge, P., 1958. Towards a post-critical philosophy. NY: Harper Torchbooks, pp.266-67.

Rhodes, C. and Beneicke, S., 2002. Coaching, mentoring and peer-networking: Challenges for the management of teacher professional development in schools. Journal of In Service Education, 28(2), pp.297-310. https://doi.org/10.1080/13674580200200184.

Richard, D.R., 2001. Technology: where students learn. American School \& University, 47(3), pp.360-363.

Riege, A. and Lindsay, N., 2006. Knowledge management in the public sector: stakeholder partnerships in the public policy development. Journal of Knowledge Management,10(3), pp. 24-39. https://doi.org/10.1108/13673270610670830.

Rodrigues, L.L. and Pai, R., 2005. Preparation and validation of KM measurement instrument: an empirical study in educational and IT sectors. In: H. Suliman, ed. 2005. Knowledge Management: Nurturing Culture, Innovation, and Technology, pp. 583-593. https://doi.org/10.1142/9789812701527 0051

Sallis, E. and Jones, G., 2002. Knowledge management in education: enhancing learning \& education. London: Kogan Page.

Shakerian, H., Dehnavi, H.D. and Shateri, F., 2016. A framework for the implementation of knowledge management in supply chain management. Procedia-Social and Behavioral Sciences, 23(1), pp.176-183. https://doi.org/10.1016/i.sbspro.2016.09.022

Shih, W.L. and Tsai, C.Y., 2016. The effects of knowledge management capabilities on perceived school effectiveness in career and technical education. Journal of Knowledge Management, 20(6), pp.1373-1392. https://doi.org/10.1108/JKM-12-2015-0515

Supermane, S. and Tahir, L.M., 2018. An overview of knowledge management practice among teachers. Global Knowledge, Memory and Communication, 67(8), pp.616-631. https://doi.org/10.1108/GKMC-08-2017-0065

Tahir, L.M., Ozay, M., Sumintono, B. and Matzain, I., 2013. Creating knowledge practices in school: exploring teachers' knowledge creation. International Journal of Humanities and Social Science, 3(1), pp.147-154.

Vandenberg, P.J., 1993. The Politics of Knowledge Dissemination: Academic Journals in Composition Studies. Dissertation. Texas Christian University.

Zhao, J., 2010. School knowledge management framework and strategies: The new perspective on teacher professional development. Computers in Human Behavior, 26(2), pp.168-175. https://doi.org/10.1016/i.chb.2009.10.009 
Zwain, A.A.A., Lim, K.T. and Othman, S.N., 2012. Knowledge management processes and academic performance in Iraqi HEls: An empirical investigation. International Journal of Academic Research in Business and Social Sciences, 2(6), pp.273-293. 